1997-01-01

\title{
Cultural Values and Education in Western Samoa: Tensions Between Colonial Roots and influences and Contemporary Indigenous Needs
}

\author{
Steven J. Hite \\ steve_hite@byu.edu \\ E. Vance Randall \\ Gaugau Va'afuti Tavana
}

Follow this and additional works at: https://scholarsarchive.byu.edu/facpub

Part of the Educational Leadership Commons

\section{Original Publication Citation}

Tavana, G.V., Hite, S.J., \& Randall, E.V. (1997). Cultural values and education in Western Samoa: Tensions between colonial influences and contemporary indigenous needs. International Journal of Educational Reform, 6(1), 11-19. https://rowman.com/Page/IJER

\section{BYU ScholarsArchive Citation}

Hite, Steven J.; Randall, E. Vance; and Tavana, Gaugau Va'afuti, "Cultural Values and Education in Western Samoa: Tensions Between Colonial Roots and influences and Contemporary Indigenous Needs" (1997). Faculty Publications. 1142.

https://scholarsarchive.byu.edu/facpub/1142

This Peer-Reviewed Article is brought to you for free and open access by BYU ScholarsArchive. It has been accepted for inclusion in Faculty Publications by an authorized administrator of BYU ScholarsArchive. For more information, please contact ellen_amatangelo@byu.edu. 


\section{Cultural Values and Education in Western Samoa: Tensions Between Colonial Roots and Influences and Contemporary Indigenous Needs}

I was six when-Mama was careless-She sent me to school-Alone-five days a week ... on my release-fifteen years after-I was handed (among loud applause from my fellow victims) - a piece of paper-to decorate my walls-certifying my release.

(Ruperake Petaia, "Kipnapped," In Seaweeds and Construction, 1983, 7, pp. 56-57).

\section{Introduction: The Western World View and Samoa}

The expansion of western culture throughout the world unavoidably alters and re-shapes the perspective of the peoples engulfed by the "West." The western "universalist" culture engenders a premium on values such as "democracy, individualism, and a high standard of living based on material productivity" (Von Laue, 1987, p. 267; Philips, 1992, p. 80). The encroachment of the western colonial era in the pacific areas of Samoa, Tonga, and the Cook Islands began around 1722 and continues in many forms to the present.

During the early colonial period in Samoa, comparisons of local culture against the western model of civilization became the rule. Early European settlers taught, and subsequently many Samoans began to accept, that European life was "better" than the traditional island lifestyle.

In Western Samoa, European colonizers character-

*Author to whom correspondence should be addressed. ized Samoans and their traditional values as "backward children," "incompetents" "uneducated," "primitives," and "simple" people. Margaret Mead's (1928) view of the Samoans is typical of the European perspective:

For such studies the anthropologist chooses quite simple peoples, primitive peoples, whose society has never attained the complexity of our own. . . . In complicated civilizations like those of Europe, or of higher civilizations of the East, years of study are necessary before the student can begin to understand the forces that work within them. . . A primitive people without a written language present a much less elaborate problem, and a trained student can master the fundamental structure of a primitive society in a few months. . . . So, in order to investigate the particular problem, I chose not to go to Germany or to Russia, but to Samoa. (pp. 14-15)

Such ethnocentric descriptions certainly ignore the truly complex meaning of the social behaviors (Spradley, 1979) and traditional lifestyle of the Samoan people. Since the arrival of the European (papalagi) colonizers, western ideologies have permeated most levels of Samoan society, particularly with regard to education. In the epigraphic poem which opened this article, Petaia (1983), a Samoan raised in Samoa, poignantly describes the essence of the "whitefication" (Wendt, 1983) of the colonized Samoans by the colonial educational system. Europeanized Samoan schools are devoted to "civilizing" the Samoans into the Western European culture, "to cutting them away from the roots of their cultures" (Wendt, 1983, p. 79), and to disrupting island and community social norms and traditional family ties (Bugotu, 1986).

Much of the formal philosophical and structural basis of the current Samoan educational system can be 
traced to the influence of a single person, C. E. Beeby. Appointed by the New Zealand government as school superintendent for Western Samoa, Beeby developed an educational model which identified the "quality" of a school system as being divided into four progressive developmental stages: (1) the Dame School stage, (2) the formalism stage, (3) the transition stage, and (4) the meaning stage (Beeby, 1966). Beeby, who became the primary figure in educational planning for school systems in New Zealand and Western Samoa, proposed that these stages are evolutionary, systematic, and hierarchical (Beeby, 1966, 1980). In order for a school system to advance to a higher stage, it must surpass the stage preceding it, in proper sequence. Although through intervention a school system may be able to advance the rate of its developmental progress, it cannot leapfrog a stage.

During Beeby's administration, education in Western Samoa was considered to be at stage two, with the potential to move to stage three, but not stage four (the stage of meaning). Rigid methods of teaching were employed, and advancement depended on individual student performance on external examinations. According to Beeby, Samoans believed such an education to be intrinsically meaningful and in accordance with traditional values $-\mathbf{a}$ belief that can be attributed to the success of the previously mentioned European Colonial effort. Consequently, the value system of traditional Samoan culture was blamed for the failure of the schools to advance to the fourth and highest stage of meaning. But Beeby himself was conscious of the flaws in his model, conceding that "it was a little disconcerting to find myself, without any sense of inconsistency, much less of shame, encouraging in Western Samoa the development of educational practices I had spent half a lifetime trying to discourage in New Zealand" (1962, p. 2).

Many Samoan parents and educators, indoctrinated by colonial agents in this perspective for more than a century, have accepted Beeby's Stages in guiding educational philosophy and praxis as appropriate. This approach is recognized as the education system that gave Europe its initial material superiority, and "any change to a more realistic and practical form of education better linked to the Samoan community and societal context is considered an attempt to 'fob' students off with something inferior" (Beeby, 1966, p. 29).

Based on this educational model, the contemporary Samoan school system administers narrow academic programs which benefit mainly the traditional elite groups. This system does not provide more comprehensive programs designed to develop and encourage skills and competencies of Samoans to ensure successful lives beyond the formal school experience. Sorely needed are educational programs that provide students with the skills needed to develop resources for survival and self-fulfillment in their rural and cultural Samoan setting (Hayden, 1971; UNESCO, 1984).

\section{Statement of the Problem}

The present educational system in Western Samoa is not meeting the needs of the majority of students who are passing through it. The Western educational philosophy and practice which drives the system does not effectively prepare Samoan students to survive in their own culture and in the larger society due to its academic bias which caters exclusively to the higher educational interests and abilities of a small minority of students. As Glasser expressed the problem, though in another context: "There is no relation between what students are asked to do with how they might use it in their lives" (1990, p. 7). The Samoan school system does not provide experiences that demonstrate "why and how" the subject content students learn can be used when they emerge from formal schooling to become full-fledged citizens of a largely agrarian Samoan society.

Education in Western Samoa is directly linked to the demands of university entrance requirements, but only a small minority of applicants are actually admitted to study at higher education echelons. The United Nations Educational Scientific and Cultural Organization (UNESCO) report on schools in Western Samoa shows that the average number of students who pass the University Entrance Examinations and then advance to a university or other institution of higher learning is a mere one percent of the total school-age population (UNESCO, 1984). Another four percent of the school population are selected for the local tertiary institutions such as the Western Samoan Teachers' College (WSTC), Western Samoan Technical Institute (WSTI), and Alafua Agricultural College-the Samoa campus of the University of the South Pacific based in Fiji. The remaining students generally do not find employment and, therefore, return to family enterprises and the traditional modes of living dissatisfied, disoriented, and ill-prepared both in attitude and in skills.

\section{Statement of Purpose}

There were five purposes for this study: (1) to verify the general problem with education in Western Samoa through integrated conceptual analysis of perceptions gathered from leaders of established Samoan social institutions; (2) to identify core Samoan cultural values which should guide the philosophy and practice of Samoan education, as stated by these leaders; (3) to assess the extent to which these values are currently integrated into the school system; (4) to identify the barriers that hinder the effective inculcation of these 


\section{All interviews were recorded.}

values; and (5) to consider possible solutions to the general problem that are consistent with Samoan culture and society. The study considered the perspectives of Samoan social leaders in schools, churches, businesses, and government, as well as the views of the matai (chiefs).

\section{Research Methods}

This was a descriptive case study, with both quantitative and qualitative components (Borg and Gall, 1989; Gay, 1995). The quantitative component was a demographic survey which identified the characteristics of the sample respondents. The qualitative component consisted of data obtained through semistructured interviews with the sample respondents. Principles and attitudes addressed in the study were extrapolated from existing artifacts to supplement the subjective data obtained in the interviews.

\section{Sample Selection}

It was determined that adequate representation of Samoan society could be obtained by identifying and sampling individuals from five major areas of Samoan social leadership: school administrators, church leaders, government officials, business leaders, and matai. Ten subjects were selected from each group by the method of purposeful sampling (Bogdan and Biklen, 1992, p. 71).

The sampling of "elite groups" (Marshall and Rossman, 1989, p. 94) for this study was based on the recognition that traditional Samoan culture is founded on representation of individual and collective needs by chosen or appointed leaders. According to this perspective, Samoan social leaders are considered to be the most influential, prominent, and well-informed individuals in and for their respective groups. Since this study is particularly oriented toward discovering the Samoan perspective on education, this method of sampling was considered to be the most credible and useful, due to the Samoan social definitions of preferred social discourse. For this reason, the responses of these individuals were collected, analyzed, contrasted, and compared in order to develop an overall perspective of the perceived problem with the Samoan educational system and a comprehensive, workable solution. All fifty individuals originally contacted participated in the study.

\section{Instrumentation}

The instrumentation for this study was comprised of a demographic questionnaire, semi-structured interviews, and educational artifacts collected in the field. Each of these mechanisms contributed directly to the expression of the Samoan perspective on education.

The demographic questionnaire was designed specifically to yield information concerning personal, institutional, and categorical demographics of the selected respondents, including age, race/ethnicity, marital status, church denomination, level of education, current employment, gender, and leadership responsibility. The questionnaire was translated into Samoan, and its accuracy was checked by matching the original English version with a "back translation" by Western Samoan educators currently teaching in Utah.

The semi-structured interviews with each of the fifty selected respondents were conducted using the analytic induction procedure to gather descriptive data (Bogdan and Biklen, 1992, pp. 69-72). This procedure employs extensive interviewing to elicit data from selected respondents in order to formulate an overall perspective. The interviews were administered at locations chosen by the respondents.

Questions were semi-structured and open-ended according to a specified pattern. They were designed to generate free, unstructured responses and to provide consistent data across the sample focused on the topics of concern. A Samoan translation of the semi-structured interviews was prepared, and its accuracy was also checked following the same procedure as that employed for the demographic questionnaire.

\section{Analysis Techniques}

All interviews were recorded on cassette tape and later transcribed. Each transcribed interview was transformed into a concept map (Novak and Gowin, 1984, pp. 119-148). The credibility of the translations and transformations was tested through the process of triangulation (Marshall and Rossman, 1989, p. 146). These concept maps were checked against three concept map transformations by individuals having extensive training in concept mapping analyses.

Concept mapping was chosen to analyze the data for this study on the following rationale: (1) it reveals the concepts and perspectives maintained by Samoan social leaders regarding the issues addressed, and (2) it allows the respondents' perspectives to be organized into "cognitive or semantic schemata-categories of meaning systematically related to one another" (Marshall and Rossman, 1989, p. 10) to facilitate solving problems (Novak and Gowin, 1984, p. 120) concerning education in Western Samoa.

Samoan people are renowned for their intelligent profusion of proverbs, legends, genealogies, and historical accounts rendered in traditional rhetorical style (Cox, 1993). One of the highest art forms in Samoa is rhetoric, narrative speaking or writing delivered with 
practiced eloquence within a specific narrative form. Such eloquence reflects the various levels of depth of one's conceptual knowledge and understanding of conditions and events. The use of concept maps to represent the responses of the participants has been valuable in distilling concepts from the narrative structure of the responses involved with this study, a style consistent with the particularly Samoan cultural frame of reference.

\section{Findings and Recommendations}

Although the findings of this study encompassed several important dimensions of education in Samoa, this section will focus on the core Samoan cultural values which respondents determined should guide education in Western Samoa in the future. Other results of the study are described and discussed in other sources (Tavana, 1994).

Samoan cultural values, which are held as central to the individual and collective identity of the Samoan people, guide all facets of their way of life. These values are essential to the stability and productivity of the council of chiefs, or matai system; the $n u ' u$, a village comprised of several families; and the aiga, or extended family, the least irreducible unit in Samoan society. It is these three units which are responsible for nurturing the fundamental aspects of Samoan culture and history. The core Samoan cultural values identified in this study as essential to an authentic Samoan educational system are respect for the elders and the matai system, deep and active care for one another, interdependence, communal collaboration, consensus in decision making, and productivity for the welfare of the larger Samoan society (see Figure 1). The following recommendations are based on the findings of the study:

\section{Recommendation \#1}

The philosophy and practice of education in Western Samoa should focus on and be consistent with core Samoan cultural values which center on respect, interdependence, cooperation, deep and active caring, consensus, the matai system, and productivity as members of society. Concern for the welfare of the community, as opposed to individual achievement, should be the primary goal of Samoan education.

Among those interviewed, there was a consistent voice indicating that there was a conflict between "outside" values and core, traditional Samoan values. As indicated by the following excerpts, the voice of the Samoan people indicates that Samoan values should become a major part of their educational system.

Matai \#1: "I can see that many of our sons and daughters have ideas of their own which are good in a way, but much of which is contrary to our own beliefs and cultural values - that are of respect, interdependence, deep and active caring, consensus, working together, and constant sharing. Consequently, they lose respect for our identity, culture, and people. They tend to care for themselves and ignore the family. They don't worry about how others are affected by their choices and decisions. Selfishness comes into play."

State Official \#1: "Respect for one another is key to our peaceful community. But we can see that this is dying out because of our exposure to the outside world. So the best thing we could do is to have our core cultural values be part of our educational system, where our young people can learn in a formal setting and practice these things in their own lives. Hence, establishing our strength as a community and creating a peaceful and safe environment for our children. Since the young people are our future leaders, and we do not wish to see these values die off, it is a must that we teach and reinforce these cultural values in the school curriculum. Once these core values become a part of the school and its operation, then it becomes easier to maintain them in Samoan society and living."

School Official \#I: "It is a mistake to put our trust on the teaching and learning of English, Mathematics, and the like, and think lightly of the importance of our own culture and the things we believe in. Respect for one [another] brings about self-discipline. To me, if our schools do not have respect for the elders and for one another, students will not be able to learn much. Since respect is a Samoan cultural value, it would permeate naturally among the school community, if it were to be adopted as part of the school. Subsequently, the school would spend little or no time on disciplining the students and would have ample time to concentrate on teaching and learning."

\section{Recommendation \#2}

The present narrow and academically-focused educational system must be replaced, as it meets the needs of only a small minority of the student population. The new system must be comprehensive, designed to enable all students to have a reasonable expectation of receiving thirteen years of relevant education, providing for the potential for post-secondary training when desired. Though high academic standards should be required, the curricular design must include useful offerings for all students. In particular, curricular offerings in vocational and agricultural skills training must be increased.

While many of the respondents indicated strong feelings in this area, one successful Samoan businessman best described the situation:

"This school system failed me, and it was only when I went to the mainland and was given the opportunity to study agriculture [that] I was able to see and find out what it was that I am good at. The current school system 


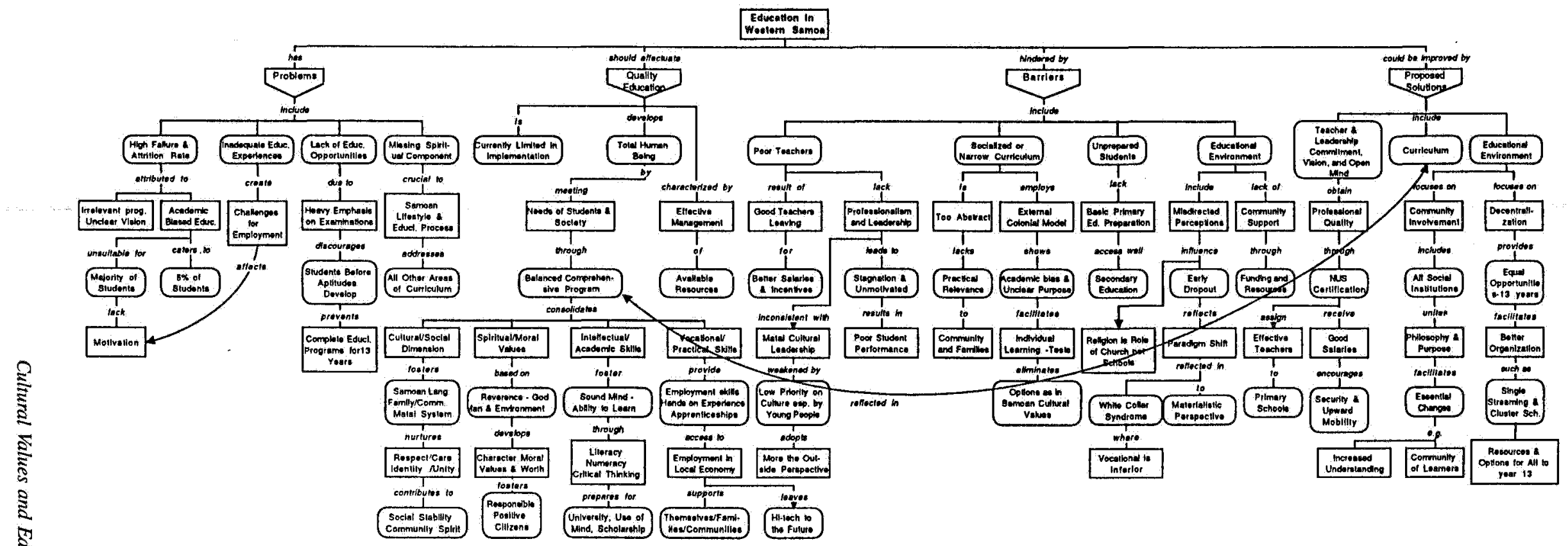

Figure 1. Consensus perspectives of Samoan social leaders concerning Samoan education. 
doesn't provide for a variety of options to suit the diversity of needs in the community-its focus is very narrow. What I would like to see happen is for the school system to provide alternative options that would allow all students to make choices based on their interests and aptitudes, and to be able to reach the final grade in the secondary level. Alternatives in areas like trades, carpentry, auto-mechanics-also agriculture, where people can utilize the land. Students must be taught alternative courses which allow them to be productive members of society in producing local foods which are healthy and fresh. You see, the current school system really teaches against these ideas. I am a good example, and I can relate to it very well, so believe me because I have been through it myself",

\section{Recommendation \#3}

Curricular design must encourage a higher degree of cooperative/group/community learning, reflecting and representing the Samoan attitudes, values, and meaning which are critical in keeping the social fabric intact. The current approach of challenging authority for the purpose of developing high-order thinking and questioning skills must be replaced with a system that promotes mutual respect and concern, including respect of the traditional leadership systems.

The conflict between cooperation and sharing curricular strategies and the style of competition currently advocated in the schools was an area of great concern. As indicated by the following excerpts, the feelings on this issue were deeply held.

Matai \#2: "Problems can be resolved much more easily when our people work together. So why on earth do they compete against each other when they can achieve results faster and better and easier when they work together and supplement each other's weaknesses? But the way the school is set up has resulted in much unnecessary competition. The competition can be very fierce. Sometimes hatred sets in because the less capable ones are not able to match their counterparts in the competitions."

Church Leader \#I: "Samoans work so hard in everything they can do for the welfare of the community, and not for individual purposes. Sometimes they place the needs of their communities over their families and over their own. If a family is building a home, the rest of the community, without being asked, would jump in and lend a handfree. This is the spirit of cooperation and true love for those who they love and associate with in the community. Therefore, the curriculum should be designed so as to accommodate these important values. It is ironic to see that our families and communities live and work together and are able to portray true and genuine love through cooperation and community togetherness, but when our children go to school, they compete against each other rather than help each other succeed. This is in conflict with our lifestyle and culture. When children see these discrepancies, they are confused and are likely to get lost in their way of thinking, believing, and valuing."

\section{Teachers must be taught strategies.}

State Official \#2: “I suggest that schools must take into serious consideration learning together as a community in the context of schools, just as it is in the context of the village communities and families in their normal experiences. Family members gather constantly to learn from each other in a direct and informal setting. They supplement each other in terms of resources, learning experiences, and more. Teachers must be taught strategies of group or community learning, where students share and learn from each other. Students must be trained in skills and encouraged to learn and study in groups, as this would enhance their learning and increase their thoughtfulness."

\section{Recommendation \#4}

Schools must continue to provide students with the resources to acquire knowledge and information. However, gaining knowledge should be focused toward making meaning and sense of the village-based world from which Samoan youngsters come and to which they return at the completion of their education, rather than mere acquisition of academic information for the sake of passing examinations.

The poor fit of the current examination-passing style of education, and the promise of a system that would prepare the students for the life most of them will experience throughout their adult lives in the villages of Samoa, comprised a major theme in the interviews. This is expressed in the words of the following individuals.

School Official \#2: "These kids go to schools, and when they come home they don't know what is expected of them in our society. After all, they do return to the village (most of them) and live in the Samoan way. You cannot run away from that. They cannot relate to real village life. I don't think they learn this in school, and they should because they are Samoan schools. What they should learn in schools is to be able to think and to understand to live a meaningful life in the village after the completion of their schooling. We do not wish that after they get educated in the secondary schools and return home that they not be able to relate to the way people live in the village and the community."

Business Leader \#2: "There is no connection between what the children are learning in school and how they live their lives. I think it is important that what they learn in school must be compatible with how they live their lives in the village community. I gather that the majority of our students do not go further than secondary schools. In fact, many of them finish at the junior secondary school. And when they leave school at that early age and are not ready to live a meaningful life, especially of that 
in the village, they are lost. I feel that the schools should prepare the children to live wherever they plan to live. That is the kind of preparation schools should look into, and not merely to prepare them to pass examinations which involve a lot of memorization-that learning is short-lived."

\section{Recommendation \#5}

Assessment of students' progress to determine advancement in school must not be based solely on pencil and paper examinations, but should include more authentic forms of evaluation which draw upon students' comprehension of social values in their Samoan context.

The use of evaluation and assessment procedures that are more compatible with the Samoan way, and the real-life experience of students both before and after their school years was promoted as being a priority in Samoan schools.

Matai \#3: "In Samoa, people relax at all times and life is fun for them. Assessing students in pencil and paper only is a serious and depressing activity, and many students who cannot relate and are unfamiliar with this experience will not feel comfortable with it, and hence fail the examinations. Assessments which are fun and relaxing in nature and where students can carry on naturally without pressure will prove more successful. Assessments where students can work in groups to deliberate and solve problems together as a team are more rewarding than individual pencil and paper examinations."

Business Leader \#3: "Group work is more rewarding and more meaningful than individual competition. Group or community work, which is the case in the village communities, gets things done faster and better than if individuals were to do it on their own. And while their efforts are being assessed, they are enjoying their experiences. Learning is evident from these informal and authentic experiences, so why not do the same thing in schools? Assess students by employment of the means that are in line or compatible with the culture and values of the Samoan society. Assessments must [be] comprised of real experiences in how students live their lives."

\section{Recommendation \#6}

The education of Samoan youth should not be considered the responsibility of schools alone. It must be recognized as the function of the aiga, nu'u, businesses, and churches. The inclusion of these other institutions would provide the impetus which is essential to educational improvement in Samoa. Future educational efforts, therefore, must include substantial and complementary input and guidance from each of these important segments of society-drawing upon the traditional cooperative Samoan social tradition.

The feelings of the respondents were particularly consistent in regard to this issue: This was true across all types of respondents, as indicated by the following:
Church Leader \#2: "I don't know why the school system does things that are contrary to the thinking and mentality of the Samoan people and their way of life. Thus, it has also become the mentality of the whole Samoan society to separate school from other institutions such as the aiga, the church, the $n u^{\prime} u$, and so forth. Because believe me that the school cannot do it alone. It goes against our own way of doing things and if they don't go together it is not going to work. Our culture assures that everyone is taken care of properly and the support of all individuals is necessary."

State Official \#3: "What is being taught in the schools must be in harmony with the way Samoan people live their lives. That is why it is vital for the community and all those who take an interest in the education of the children to be involved in the planning and operation of the school. The school talks as if they can function without the support of the community, but it is not possible. If the support and expertise of the community including the aiga, nu' $u$, church, government, and business is utilized to the maximum, the schools will benefit a great deal. After all, students will return to the community to work and live. So it is a must for the schools to include other institutions in their operation."

\section{Recommendation \#7}

Consensus should be central in decisions and deliberations at all levels of education: classroom, faculty, and administrator deliberations, etc. Seeking consensus would encourage context-appropriate dialogue, which would increase depth in thinking and enhance the development of the intellectual-cognitive mind.

The use of consensus in the educational system is of particular importance in Samoa. Consensus is the central feature in Samoan social discourse, it is the way of Samoan deliberation and decision making. As one Matai put it:

"In the village fono (meeting), matai deliberate over matters pertaining to the good of the village and the families. Deliberations continue until everyone agrees; then the final decision is made. You will find that as the matai relate these decisions to their respective families, the people give their full support to the decisions and are able to adhere to them. People are happy when decisions are made collectively, knowing that they have taken part in it. They feel good about themselves as they become very much a part of the decision-making process."

The respondents felt, however, that the educational system did not incorporate this important mechanism of discourse and social interaction in the curriculum. The responses of the following School Official and Matai were typical for the respondents in all groups of the study:

School Official \#3: "We have discovered that as we include the staff and students in the decision-making process, they always give full support for that decision. This is not a common practice in many schools because of the

Cultural Values ind Education in Western Samoa 
structure of the school system, which is very authoritative, and because teachers tend to push for coverage of the curriculum to meet the national and external examinations criteria and do not wish to spend the time deliberating for classroom consensus."

Matai \#4: "When students go to school, teachers make decisions for them. Again very different from the way the Samoans make their decisions, especially when it involves serious matters. The school must indeed follow suit and be able to let the decisions and solutions to the problems be discussed and then let decisions be reached by consensus. Through constant deliberations and interactions, students will be able to develop deep thoughts about the decisions that they make."

\section{Recommendation \#8}

The system of formal learning should be designed to complement the informal learning which constantly takes place in the community. Formal learning should build upon and expand on the experiences students bring with them from the village community. According to many of the respondents, the disconnection between formal and informal learning creates considerable conflict between the real life of the village and the too-academic life of the schools.

Matai \#5: "I have a son who has learned a lot from his experiences at home and during many village gatherings; to me, he is very smart. He knows his place in society. He has a lot of respect for the elders and people he comes in contact with. But at high school, his teachers have been saying that he is not smart-but $I$ know he is. Maybe what he is learning in school does not relate to what he learns at home, or what he already knows from his informal experiences in the village. I never went to a palagi (european) school. But I tell you that I can figure out any complicated problem and come up with better solutions than any of those of my age group who have been through formal training. So, do not ignore the informal experiences because they can be good steppingstones to better and higher learning in more formal settings."

Church Leader \#3: "Most of the best decisions made in the village community and society are by the matai, who have never had any formal schooling. So through their daily experiences, they have learned to think fast and deep. The same thing could happen to our young people. Through their informal training in their homes, villages, and society, they become more learned of the things of the world they live in. So why not extend that learning into the schools from the things they already know from their informal experiences to the new knowledge they intend to learn in school? School should plan their curriculum based on these principles."

School Official \#4: "When students go to school, teachers do not consider the vast amount of knowledge they already bring with them from the home. I have been through that myself when I was a teacher for many years. Teachers tend to teach from books as if children do not know anything at all, yet you will be surprised at how much they can talk about even when they first start school. Schools should be an extension of the home, in terms of what the students learn. Schools should reinforce the learning that naturally goes on continually in the environment - it is not necessary to separate the two. They should complement each other. Since students bring from the home a lot of learning experiences based on what they already know, the teachings provided by the school should then help complement that learning and not to be in conflict with it."

\section{Recommendation \#9}

Schools should follow the pattern inherent in the village community, whereby all members are honored for their contribution-whatever it may be-to the welfare of the community as a whole. Individual achievement must no longer be considered as the epitome of performance; cooperative learning and group achievement must emerge as the mode of education. As supported by the following excerpts, the Samoan view of cooperation, individual worth, and community as opposed to individual achievement, stand in stark contrast to the values modeled in the schools.

Business Leader \#4: "Everyone's contribution to the good of the community and society is important. Regardless of what it is, large or small, they are all valuable to the good of all. Group contributions are very valuable. It is the people that make up the group. Each person has to be independent first in order for the group to become interdependent. From group contributions, it provides the community the spirit of synergism which is very much needed for the betterment of society today. Schools should follow such principles where group performances in class projects can really help build high morale and self-esteem and where the group can advance together as a whole rather than as individuals. When the school is operated in such a way, everyone feels good, is happy and is more willing to proceed for better things and success."

Church Leader \#3: "In Samoa, everyone is the same. Everyone has love for everyone else. There are no boundaries. That is why community work is vital in Samoan living. Look at the times when the village built our damaged home. Everyone came-adults, children, young people. They all wanted to take part in the process. They come together, talk, eat, laugh, and get the work done twice as fast. Everyone is happy to serve and that is fa'a Samoa. In the context of the schools, the same thing could be done there where the contributions from all students, teachers, and school administrators are important for the good of the school and for everyone. Whether it is in the classroom or out in the field playing or doing service projects, everyone's contribution must be honored and respected because they are all valuable. By following this, students will continue to be inspired to contribute more in a more positive and loving way for the good of society. It also develops within them the princi- 
ple of selfless service which is core to the Samoan people and living."

\section{Summary}

Contemporary Samoa is at a cultural, philosophical, and educational crossroad. The Samoan people desire to preserve their indigenous culture, with its traditions, mores, and protocols. Many aspects of this culture, however, have been significantly influenced historically by European colonialism and recently by technological proliferation; both influences have served to hybridize its religious, economic, social, and political character. Such changes have generated a conflict in the attitude and perspective of the Samoan people: How much of the old should be extolled and maintained, and how much of the new must be assimilated?

Education in Western Samoa does not have an existence separate from and independent of the society it serves. It is not a self-sufficient entity; its operation is inextricably tied to the functioning of other established institutions such as the family, the church, the village, and the matai, and, in significant part, it draws inspiration for the formulation of its philosophy and praxis from these political, religious, and social entities. The operation of all these institutions, of course, is guided by the values inherent in the culture and transmitted by it.

This resolved, the education system is obligated to effectively integrate these values that are a fundamental part of the Samoan community, the $n u ' u$, and the aiga into the curricula and pedagogy of the schools. Notions of respect for the elders, communal collaboration and unity in the face of challenge and adversity, interdependence of family members and community subgroups, and active mentoring, among other traditional behaviors, must be conveyed and modeled in classrooms by teachers and school administrators. These social behaviors must also be modeled in the homes by parents, in the nu'u by the matai, in the churches by religious leaders, in the business community by its leaders, and in the government by politicians who understand the traditions of Samoa's past and are responsible for shaping its future.

\section{References}

Beeby, C. F. 1962. "Stages in the Growth of a Primary School Education System," Comparative Educational Review, 16(1):2-11.

Beeby, C. E. 1966. The Quality of Education in Developing Countries, Cambridge, MA: Harvard University Press.

Beeby, C. E. 1980. "The Thesis of Stages Fourteen Years Later," International Review of Education, 26:451-474.

Bogdan, R. C. and Biklen, S. K. 1992. Qualitative Research for Education: An Introduction to Theory and Methods, 2nd ed., Boston: Allyn Bacon.

Borg, W. R. and M. D. Gall. 1989. Educational Research: An Introduction, 5th ed., New York: Longman.

Bugotu, F. 1986. "Island Countries Ask, 'Education for What?' " Bulletin of the UNESCO Regional Office for Education in Asia and the Pacific, 27:198-207.

Cox, P. A. 1993. Nafanua: Saving the Samoan Rainforest, Unpublished manuscript, Brigham Young University.

Gay, L. R. 1995. Educational Research: Competencies for Analysis and Application, 5th edition, Columbus: Merrill Publishing Company.

Glasser, W. 1990. The Quality School: Managing Students Without Coercion, New York: Harper \& Row Publishers.

Hayden, H. 1971. "On the Quality of Education in the South Pacific," International Review of Education, 17(2):165-179.

Marshall, C. and G. B. Rossman. 1989. Designing Qualitative Research, London: Sage Publication.

Mead, M. 1928. Coming of Age in Samoa, New York: Blue Ribbon Books.

Novak, J. D. and D. B. Gowin. 1984 Learning How to Learn, London: Cambridge University Press.

Petaia, R. 1983. “Kidnapped," A Pacific Island Collection-Seaweeds and Construction, 7:56-57.

Philips, S. U. 1992. "Colonial and Post Colonial Circumstances in the Education of the Pacific Peoples," Anthropology and Education Quarterly, 23:73-82.

Spradley, J. P. 1979. The Ethnographic Interview, New York: Holt, Rinehart \& Winston.

Tavana, G. V. 1994. "Cultural Values Relating to Education in Western Samoa: A Conceptual Analysis of the Perspectives of Samoan Social Leaders," Unpublished Doctoral Dissertation, Provo, UT, Brigham Young University.

UNESCO. 1984. Technical and Vocational Education in Western Samoa, Bangkok: UNESCO Regional Office for Education in Asia and the Pacific.

Von Laue, T. H. 1987. "The World Revolution of Westernization," The History Teacher, 20(2):262-279.

Wendt, A. 1983. “Towards a New Oceania," A Pacific Island Collection-Seaweeds and Construction, 7:70-85. 